\title{
Aftandil S. Erkinov. The Andijan Uprising of 1898 and Its Leader Dukchi-Ishan Described by Contemporary Poets. Foreword by Bakhtiyar Babadjanov
}

\section{Alexandre Papas}

\section{OpenEdition}

Journals

Édition électronique

URL : http://journals.openedition.org/abstractairanica/40786

DOI : 10.4000/abstractairanica.40786

ISSN : 1961-960X

Éditeur :

CNRS (UMR 7528 Mondes iraniens et indiens), Éditions de l'IFRI

Édition imprimée

Date de publication : 1 décembre 2013

ISSN : 0240-8910

\section{Référence électronique}

Alexandre Papas, «Aftandil S. Erkinov. The Andijan Uprising of 1898 and Its Leader Dukchi-Ishan Described by Contemporary Poets. Foreword by Bakhtiyar Babadjanov », Abstracta Iranica [En ligne], Volume 32-33 | 2013, document 300, mis en ligne le 01 juillet 2016, consulté le 29 septembre 2020. URL : http://journals.openedition.org/abstractairanica/40786 ; DOI : https://doi.org/10.4000/ abstractairanica.40786

Ce document a été généré automatiquement le 29 septembre 2020.

Tous droits réservés 


\title{
Aftandil S. Erkinov. The Andijan Uprising of 1898 and Its Leader Dukchi-Ishan Described by Contemporary Poets. Foreword by Bakhtiyar Babadjanov
}

\author{
Alexandre Papas
}

\section{RÉFÉRENCE}

Aftandil S. Erkinov. The Andijan Uprising of 1898 and Its Leader Dukchi-Ishan Described by Contemporary Poets. Foreword by Bakhtiyar Babadjanov, Tokyo, The University of Tokyo, 2009, 118 p. (Central Eurasian Research Series, No. 3).

Dans sa préface à l'étude d'Aftandil Erkinov, Bakhtiyar Babadjanov explique comment la tristement célèbre révolte d'Andijan (vallée du Ferghana) de 1898 fut interprétée par les observateurs russes de l'époque. Tandis que la presse se déchaîna contre cette nouvelle scorie de "la question musulmane», experts et autorités régionales produisirent, dans la crainte d'un embrasement, plusieurs documents qui recommandaient une prise en charge de l'éducation comme de la justice en vue d'une assimilation des populations musulmanes. Du côté des colonisés, la réaction fut évidemment différente. Néanmoins - et c'est toute la thèse que défend A. Erkinov dans son introduction - elle ne se réduit guère à un cri unanime de haine contre le tsar ou l'empire russe. Si l'insurrection de Dukchi Ishān (1852-1898) fut perçue par certains comme un djihad légitime dirigé par un saint, elle fut condamnée par d'autres, en particulier des poètes, qui n'hésitèrent pas à publier des vers satiriques dans lesquels le leader était couvert d'injures et constamment critiqué. Après avoir introduit chacun des auteurs, l'ouvrage présente une édition des pamphlets, le plus souvent en caractères arabes. Tous les textes présentés ici sont écrits en langue turkī. C'est une 
édition précieuse étant donné l'éparpillement de ces poèmes conservés dans divers fonds d'Ouzbékistan.

2 À la lecture de cette savante étude, une question demeure : l'hostilité caustique des poètes - peu importe qu'elle fut pleinement assumée ou bien encouragée par les autorités coloniales - n'est-elle pas autre chose que le discours d'une petite élite oserait-on dire de classe ? - qui, fidèle à ses habitudes de cour, inquiète du désordre social, s'évertuait à étouffer toute initiative populaire?

\section{AUTEURS}

\section{ALEXANDRE PAPAS}

CNRS, Paris 